\title{
Lev Jakubinski (1892-1945): o destino de um linguista russo. ${ }^{1}$
}

Irina Ivanova

Professora da

Universidade de

Lausanne - Suíça, Área

de línguas eslavas.
Resumo: Apesar de Lev Jakubinsk (1892-1945) ter sido um dos fundadores do movimento do formalismo russo, uma fonte de ideias para a teoria do dialogismo de Volochinov (1895-1936) e um autor de referências para L. Vigotski (1896-1934), seu nome permanece desconhecido no Ocidente. 0 presente artigo busca cobrir essa lacuna e descreve o percurso científico desse linguista russo que, em seus trabalhos, apresentou muitas ideias inovadoras para sua época. Além disso, a vida e o percurso científico de Lev Jakubinski são uma porta aberta para as discussões e as aspirações dos cientistas dessa época, quando as tormentas sociais coincidiam com o desenvolvimento intensivo das ciências naturais e sociais.

Palavras-chave: Dialogismo. Diálogo. Linguística da fala. Língua viva. Marxismo. Linguística russa soviética.

Tradução de Luiza Guimarães-Santos, Mestre em Letras, Língua e Literatura francesa pela Universidade de São Paulo. Revisão técnica de Mauricio Érnica. 
O nome de Lev Petrovich Jakubinski permanece pouco conhecido pelos especialistas em história da linguística, apesar de ele ter desempenhado um papel de primeiro plano na linguística soviética das décadas de 1920-1930. Como lembra o linguista Ruben Budagov (1910-2001), "em cada uma de suas obras, Jakubinski [...] indicava, formulava e analisava problemas que, mais tarde, se tornaram objeto de estudo de outros cientistas" (BUGADOV, 1988, p. 129). É possível compartilhar esse ponto de vista na medida em que algumas das ideias formuladas por Jakubinski em seus artigos foram desenvolvidas por outros linguistas na segunda metade do século XX.

Assim como Viktor Chklovski, Jakubinki foi fundador da Sociedade de estudos da linguagem poética (OPOJAZ) (IVANOVA, 2009). Ele esteve, igualmente, entre os precursores da criação do Instituto da Palavra Viva (Id., 2006) e na origem da sociolinguística na Rússia. Ele foi também o primeiro linguista a definir os princípios da análise do diálogo. As ideias de Jakubinski foram desenvolvidas tanto no livro Marxismo e filosofia da linguagem de V. Volochinov (1895 -1936), quanto em Pensamento e linguagem de L. Vigotski (1896-1934). Na década de 1930, Jakubinski ensinou em diversas instituições de ensino superior e conduziu uma intensa atividade administrativa de organização da pesquisa científica em Leningrado. No entanto, ele caiu no esquecimento logo após sua morte em 1945. Sua última obra fundamental, Istorija drevnerusskogo jazyka [História do russo antigo] (JAKUBINSKI, 1953), só foi publicada em 1953, por iniciativa de seu antigo colega Viktor Vinogradov (1894-1969), que se tornara, após a “discussão linguística de 1950", diretor do Instituto de linguística da Academia de Ciências da URSS.

Cerca de cem anos nos separam do início do século XX. Hoje, é tempo de nos voltarmos para a evolução das ideias científicas, incluindo as ideias linguísticas na Rússia, ocorridas em um período tão complexo e rico como foram as décadas de 1920-1930 depois que a revolução de 1917 sacudiu a vida sociopolítica e estimulou o desenvolvimento das ciências naturais e humanas.

Jakubinski teve uma participação ativa nessas transformações. Sua obra também é representativa, portanto, das discussões de uma época que viu, verdadeiramente, o nascimento da linguística do século XX. Pode-se dizer que Jakubinski serve de fio condutor para entrar na problemática dessa época.

Em 1986, o psicólogo Alexis Leontiev (1936-2004), um dos fundadores da psicolinguística soviética, publicou vários trabalhos de Jakubinski em uma antologia intitulada Jazyk $i$ ego funkcionirovanie [A linguagem e seu funcionamento] (JAKUBINSKI, 1986), para a qual ele redigiu um prefácio e 
alguns comentários. Em seu prefácio, ele destacou o artigo de Jakubinski "Sobre a fala dialogal", apresentando-o como o trabalho mais importante de Jakubinski (opinião distinta da de Budagov e de Vinogradov, para os quais a sua obra principal era Istorija drevnerusskogo jazyka [História do russo antigo]). Defendendo a importância desse artigo, Leontiev apontava que algumas de suas ideias eram comuns à teoria do diálogo de Mikhail Bakhtin (1895-1975) (LEONTIEV, 1986).

Assim, se o nome de Jakubinski reapareceu na história das ideias linguísticas, foi graças ao interesse de pesquisadores, tanto de linguística quanto de análise literária, na obra de Mikhail Bakhtin e nas discussões em torno da questão da autoria de seus trabalhos. Parece que a recente tradução em francês do livro de Volochinov Marxismo e filosofia da linguagem, cuja atribuição a Bakhtin é totalmente rejeitada, e as traduções em línguas europeias e não europeias desse mesmo livro, desempenharam um papel especial nesse processo e provocaram uma recuperação do interesse nas origens da teoria do diálogo e do dialogismo na linguística russa. A recente publicação da tradução em francês das obras-chave de Jakubinski² também fornece uma informação importante sobre o contexto do nascimento dessa teoria.

Lev Petrovich Jakubinski nasceu em Kiev, em julho de $1892^{3}$, em uma família de militares. Seu pai, Petr Vasilievich, era tenente-general e dirigia a Academia de economia militar de Kiev, cargo que ele manteve após a Revolução de outubro de 1917. De acordo com o testemunho de L. Jakubinski (1986), seu pai encarregou-se da reorganização dessa academia depois da revolução, atuando como professor e reitor da faculdade técnica. Ele recebeu, pelo trabalho realizado, uma menção de reconhecimento do Comité militar revolucionário (decisão $\mathrm{n}$ 1317 de 28 de outubro de 1924) “por sua atuação altamente eficaz na instrução do comando do Exército vermelho, apesar das condições difíceis”. Notemos que era extremamente raro que um oficial de alto nível do exército czarista recebesse um sinal de reconhecimento do governo revolucionário. Essa era a época em que o jovem Exército vermelho ainda precisava da experiência de antigos oficiais militares transferidos para o serviço do novo poder. Porém o tempo das repressões políticas não estava muito longe.

Cf.: JAKUBINSKI, Lev.Une linguistique de la parole (URSS, années 1920-1930) [Lev Jakubinski, uma linguística da fala (URSS, décadas de 1920-1930)]. Textos editados e apresentados por Irina Ivanova, tradução para o francês de Irina Ivanova e Patrick Sériot. Lambert-Lucas, 2012.

3 O dia exato de seu nascimento não é indicado no registro mantido nos arquivos do Instituto pedagógico Herzen em São Petersburgo (arquivo pessoal n ${ }^{1931) .}$ 
Petr Vasilievich morreu em 1931, tendo se aposentado do exército por razões de saúde e de idade. A mãe de L. Jakubinski, Marija Livovna, era francesa (seu nome de solteira era Danican-Philidor), razão pela qual ele falava perfeitamente, desde a infância, o francês assim como o russo. Ele tinha um irmão caçula, Vasili (nascido em 1894), e uma irmã caçula, Maria (nascida em 1899).

Lev Jakubinski fez seus cinco primeiros anos de estudo no ginásio (ensino médio) n 5 de Kiev, depois, seguindo sem dúvida o exemplo paterno, entrou na Escola de cadetes militares para completar o ensino médio. Uma carreira militar parecia se abrir diante dele, mas ele preferiu entrar na Universidade São Vladimir em 1909. Ele foi estimulado, com certeza, pelo seu interesse precoce pela literatura e pelas línguas, pois na sua lista de publicações aparece que, em 1908-1909, ele tinha publicado na revista Literaturnonaučnyjsbornik [Antologia científica e literária] ensaios sobre Byron, Balmont, além de poemas. Em seus primeiros trabalhos, ele aborda a questão da unidade da forma e do conteúdo, os procedimentos que contribuem para 0 caráter poético de um texto, e ele estuda também as obras de A. Veselovski, A. Potebnja e F. Buslaev. É possível pensar que o seu interesse pela literatura determinou a escolha de sua futura profissão.

Em 1909, ele entrou, portanto, na Universidade de Kiev, onde ficou apenas pouco tempo, pois, no mesmo ano, ele foi para a Universidade de São Petersburgo, no departamento de estudos russos e eslavos da Faculdade de filologia e história. É preciso dizer aqui algumas palavras sobre o ambiente que reinava nessa faculdade a fim de compreender como se formaram os princípios científicos de Jakubinski.

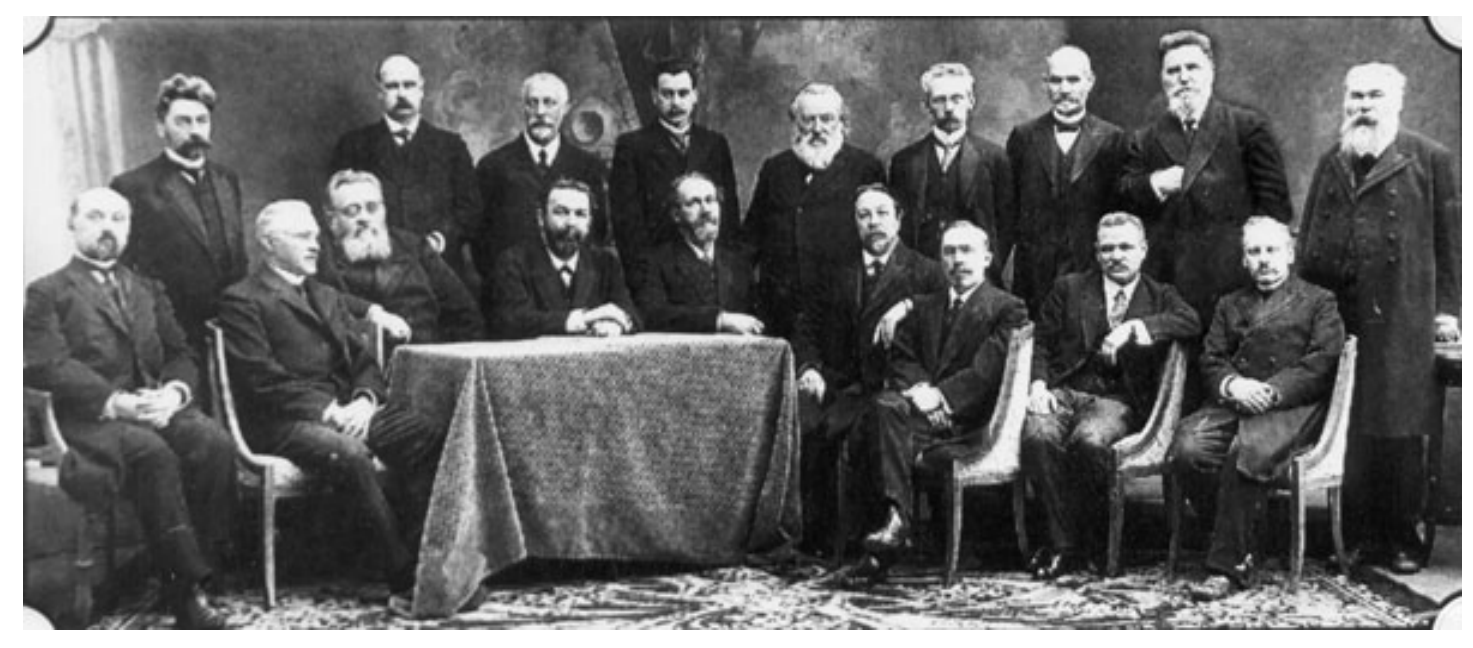

Os professores da Faculdade de filologia e história em 1 de outubro de 1913 (da esquerda para a direita, sentados: B.A. Turaev, S.F. Platonov, I.Ja. Sliapkin, F.A. Braun, F.F. Zelinski, S.K. Bulich, S.A. Zebelev, M.I. Rostovcev, A.A. Saxmatov; em pé: D.V. Ainalov, D.K. Petrov, I.M. Grevs, A.I. Vvedenski, N.I. Kareev, E.D. Grimm, I.A. Baudouin de Courtenay, I.D. Andreev, P.A. Lavrov. 
A Faculdade de filologia e história incluía não apenas os departamentos de línguas e literaturas, mas também os de história e de filosofia, que incluía a psicologia. Por essa razão, a temática dos cursos era muito variada: da análise de textos literários antigos à história da música, passando por questões de filosofia, de sociologia e de psicologia. Os cursos e seminários aconteciam não apenas dentro dos muros da Universidade, mas também no Instituto psico-neurológico, fundado porV. Bekhterev (1857-1927, conhecido no Ocidente com sua ortografia alemã: Bechterew) em 1908, e nos apartamentos de alguns professores.

O ensino de disciplinas linguísticas era organizado de acordo com a abordagem histórico-comparativa, tradicional naquela época. É por isso que os programas incluíam inúmeras línguas antigas. Mas a Universidade de São Petersburgo também recebia linguistas famosos, como J. Baudouin de Courtenay (1845-1929)4, A. Saxmatov (1864-1920) e M. Vasmer (18861962). Aos poucos, graças a eles, novas abordagens em linguística foram sendo desenvolvidas. Baudouin de Courtenay desenvolvia sua concepção de linguagem como atividade, introduzindo novos métodos de estudo da língua viva que serviram de base para o seu curso de introdução à linguística. Em 1909, já funcionava o Laboratório de fonética experimental, criado em 1899 por outro estudante de Baudouin, Sergei Bulich (1859-1921)5. Também em 1909, a direção do laboratório passou a L. Scerba (1880-1944), que tinha acabado de voltar de Paris depois de um estágio com o abade Rousselot. Ele começou, imediatamente, a trabalhar em sua teoria do fonema, cujas teses gerais ele publicou em seu livro Russkie glasnye $v$ kačestvennom $i$ kolivestčennom otnošenii [As vogais russas sob o aspecto qualitativo e quantitativo]. Por sua vez, A. Saxmatov, conhecido por seus trabalhos em dialetologia eslava e em história do russo, começava a elaborar uma teoria sintáxica que lançava as bases da abordagem comunicacional dos fenômenos de linguagem. Ele também estudava a língua sob seu aspecto vivo, especialmente as questões da transmissão fonética da fala.

J. Baudouin de Courtenay obteve, graças à ajuda de Saxmatov, um cargo de professor titular na Universidade de São Petersburgo e lecionou na Faculdade de filologia e história de 1901 a 1918. Ele era conhecido não só por suas ideias científicas inovadoras, mas também por suas opiniões políticas democráticas. Em torno dele se formou um grupo informal de seus alunos, mais tarde conhecido sob o nome de "Escola linguística de São Petersburgo". Muitos de seus membros eram próximos do formalismo russo (L. Jakubinski, L. Scerba, E. Polivanov, B. Larin, S. Bernstein). Os cursos de Baudouin de Courtenay eram seguidos por formalistas, como V. Chklovski, S. Bondi, Ju. Tynianov e B. Eichenbaum. Posteriormente, diversos pesquisadores deram prosseguimento às suas teorias na linguística soviética, entre os quais S. Bernstein, B. Larin, L. Scerba, L. Jakubinski, L. Zinder, M. Matusevich. Foi desenvolvendo a sua abordagem que L. Scerba e seus alunos criaram a Escola fonológica de Leningrado.

S. Bulich foi aluno de Baudouin de Courtenay na universidade de Kazan. Nomeado professor na Universidade de São Petersburgo em 1891, ele se interessava pelos problemas de entonação, de ritmo e de música (Cf. IVANOVA, 2003). 
No domínio da literatura e da crítica literária, a Faculdade de filologia e história continuava a tradição de Aleksandr Veselovski (1855-1906) ${ }^{6}$, conhecido por seu método formal de análise de obras literárias. Embora o seu trabalho para criar uma poética histórica e uma teoria da poética tenha ficado inacabado, ele conseguiu formar uma plêiade de críticos literários que continuaram sua obra. Entre os mais famosos estão V. Zirmunski (1891-1971), V. Propp (18951970)7, V. Sismarev (1875-1957) ${ }^{8}$ e B. Eichenbaum (1886-1959)9. Naquele tempo, havia também o seminário de Semen Vengerov (1855-1920) ${ }^{10}$. Este último não compartilhava o interesse de Veselovski pelos métodos formais, porém, quando seus alunos começaram a se entusiasmar com essa abordagem, ele lhes deu total liberdade para escolher os temas e métodos de análise das obras poéticas. As discussões ao longo do seminário de Vengerov contribuíram para a elaboração das teorias dos formalistas russos e para a clarificação da oposição “linguagem poética/linguagem prática”.

Foi assim que Jakubinski encontrou na Universidade de São Petersburgo um ambiente criativo, no qual professores de vanguarda, junto com os seus alunos, aplicavam novos métodos, organizavam discussões sobre os temas atuais da filosofia e da psicologia e debatiam os avanços da ciência e das $\operatorname{artes}^{11}$.

Na Universidade, Jakubinski recebeu uma formação completa em "filologia”, como era chamada a disciplina que não separava o estudo da literatura daquele da língua. Em 1911, Jakubinski escreveu seu primeiro artigo científico como estudante: "Os zeros psicofonéticos no pensamento linguístico russo", o qual

6 A. Veselovski, etnógrafo, especialista em história e literatura e professor da Universidade de São Petersburgo. Ele foi o primeiro, na crítica literária russa, a buscar aplicar métodos formais de análise de obras literárias e a fundar a base teórica da poética histórica. Suas ideias tiveram uma grande influência sobre o formalismo russo.

7 V. Propp, um dos fundadores do estruturalismo na análise de obras literárias e de folclore, autor da Morfologia do conto (1928).

8 V. Sismarev era romanista, acadêmico e foi por muito tempo titular da área de filologia romana na Universidade de Leningrado. Seus estudos tinham como campo a história da poesia francesa e provençal, da literatura italiana, a gramática histórica do francês. Ele é o autor de um dicionário de francês antigo.

9 B. Eichenbaum foi um dos fundadores do formalismo russo. Seu artigo "Kaksdelana 'Šinel' Gogolja” [Como é feito 'O Capote’ de Gógol] (1919) foi um dos primeiros modelos de analise formalista de um texto literário.

10 S. Vengerov, um dos maiores especialistas na obra de Pouchkine, iniciou o grande dicionário da língua de Pouchkine. Seu seminário sobre Pouchkine, organizado em 1908, era muito conhecido em São Petersburgo; é lá que se formavam diversos futuros críticos literários.

${ }_{11}$ Sabe-se que Baudouin de Courtenay participou dos debates dos futuristas. Como resposta aos seus manifestos, ele escreveu dois artigos "Slovo i "slovo" [A palavra e o que se chama de palavra'] e "K teorii 'slovakaktakovogo' i 'bukvykaktakovoj”” [Pela teoria da 'palavra enquanto tal' e da 'letra enquanto tal'] (1914). Nesses artigos ele expressava sua opinião sobre as experiências linguageiras dos futuristas. 
Ihe valeu uma medalha de prata, graças à avaliação positiva de Baudouin de Courtenay, evidenciando a acuidade científica e o rigor de pensamento do seu autor.

Em 1913, Jakubinski completa seus estudos, mas ele obtém uma posição de bolsista de tese a fim de se preparar para a carreira de professor. Paralelamente, ele começa a ensinar em diversos estabelecimentos de ensino de São Petersburgo (que passou a se chamar Petrogrado em agosto de 1914).

A participação de Jakubinski na criação da OPOJAZ apresenta algum interesse. V. Chklovski (1893-1984) ${ }^{12}$ relata que ele havia enviado a Baudouin de Courtenay seu trabalho recém-publicado Voskrešenieslova [A ressureição da palavra] (1914), que, por sua vez, o encaminhou a Jakubinski (CHKLOVISKI, 1973, p. 103). Segundo Chkolovski, “o dia do meu encontro com Lev Petrovich foi notável. Nós falamos sobre teoria durante uma ou duas horas (Id., 1990, p. 487). Jakubinski me explicou a diferença entre a função poética e a função prosaica da linguagem. A partir desse momento, nós fomos inseparáveis”. Esse papel importante desempenhado por Jakubinski na criação da OPOJAZ é confirmado por Ju. Tynianov em suas memórias ${ }^{13}$.

Essa observação de Chklovski nos faz pensar que, por volta de 1916, Jakubinski se interessava muito pela especificidade respectiva da linguagem poética e da linguagem prática, por isso, não é surpresa que ele tenha publicado três artigos sobre esse tema nas duas primeiras coletâneas da OPOJAZ. Outros formalistas russos citaram, repetidamente, esses artigos, o que demonstra a autoridade do linguista junto a críticos literários ${ }^{14}$. Em uma de suas cartas a Jakubinski, no fim da década de 1920, Chklovski o elogia por seu ceticismo saudável de especialista das ciências da natureza, herdado de Baudouin de Courtenay(CHKLOVSKI, 1990, p. 306). Essa apreciação diz muito sobre os métodos de trabalho de Jakubinski e sobre sua reputação junto aos formalistas russos.

Em 1917, Jakubinski passa de forma exitosa em três das quatro provas necessárias para a obtenção de um cargo de professor na universidade. Paralelamente às suas atividades de professor, ele se encarrega da administração e da organização. Em 1918, é possível encontrar seu nome na

${ }_{12}$ V. Chklovski, um crítico literário russo soviético muito conhecido. Ele foi um dos fundadores da Sociedade para os estudos da linguagem poética (OPAJAZ) em Petrogrado e seu primeiro presidente.

${ }_{13}$ Segundo o testemunho de Ju. Tynianov, Jakubinski e Chklovski iniciaram a criação da OPOJAZ, e a eles se juntaram, em seguida, outros linguistas e críticos literários (cf. comentários de M. Chudakova em Tynianov, 1977).

14 Em seu livro Formal'nyjmetod $v$ istoriiliteratury [0 método formal na história da literature] (Leningrado, 1927), B. Engeligardt coloca Jakubinski no mesmo plano que Jakobson. 
lista dos organizadores do Instituto da Palavra Viva ${ }^{15}$. Nesse estabelecimento, ele leciona cursos sobre a evolução da linguagem e a semântica. Ainda em 1918, ele entra na Comissão do Narkompros [Comissariado do povo para a instrução] para a organização de uma academia pedagógica. De 1919 a 1923 , por razões desconhecidas, ele se dedica cada vez mais à educação básica.

Ao mesmo tempo em que trabalha na escola básica, Jakubinski continua seu trabalho sobre a linguagem poética e a linguagem prática, mantendo seus contatos com a OPOJAZ. Ele republica seus primeiros artigos sobre esse tema nas coletâneas Poètika ${ }^{16}$ e publica dois novos trabalhos: $O$ poètičeskom glossemosočetanii [Sobre a combinação glossemática poética] e Otkuda berutsja stixi [De onde vêm os versos?]. Nesses artigos, encontram-se ecos das discussões sobre as especificidades da linguagem poética conduzidas pelos formalistas russos e pelos pesquisadores próximos a eles.

Em 1921, Jakubinski renova seu vínculo com a Universidade de Petrogrado e se torna colaborador científico do ILJaZV (Instituts ravnitel'nogo izučenija literaturijazykov Zapada i Vostoka: Instituto de estudos comparados de línguas e literaturas do Oriente e do Ocidente), que dependia da Universidade ${ }^{17}$. Esse instituto de pesquisas tinha como objetivo realizar o programa de Veselovski, que consistia em criar métodos exatos de análise comparada de obras da literatura mundial.

Nessa época, os interesses de Jakubinski são muito amplos: vão do aspecto fonético da linguagem poética às questões de sociolinguística e à linguística histórica. Esse amplo espectro de interesses científicos deve ter desempenhado um papel importante em sua nomeação na universidade: ele se revela um especialista tanto em linguística histórica, tradicional, quanto em novas direções: sociolinguística, estilística, teoria da linguagem poética.

No entanto, mesmo levando-se em consideração essa variedade, seu artigo O dialogičeskoj reči [Sobre a fala dialogal], publicado em 1923 na revista

15 Zapiski Instituta Živogo Slova, vyp. 1, Petrograd, 1919, p. 37. [Notas do Institudo da Palavra Viva].

16 Jakubinski, 1919 : «Skoplenie odinakovyx plavnyx v praktičeskom i poetičeskom» [Acumulação de soantes idênticos na linguagem prática e na linguagem poética] in Poètika, Petrograd, pp. 37-49. Jakubinski,1919 : « Osuščestvleniezvukovogoedinoobrazi ja v tvorčestveLermontova » [A realização da uniformidade sonora na obra de Lermontov], in Poètika, Petrograd, pp. 50-57.

${ }_{17}$ Criado em 1923, o ILJaZV era a transformação do Instituto de história comparada das literaturas do Ocidente e do Oriente ("Instituto Veselovski"), o qual funcionava desde 1921. Em 1929-1930, o ILJaZV havia se tornado autônomo, mas se encontrava no território da Universidade. Em 1930, ele foi transformado em Instituto da cultura linguageira (Institutrečevojkulitury). Em 1932, sua seção literária foi eliminada e sua seção linguística se tornou o Instituto de linguística da Academia de ciências (Lutovinova, 2007, p. 138). 
Russkaja reč ${ }^{\prime 18}$, surpreende pelo caráter inesperado de sua problemática. Ele propõe a criação de uma nova linguística e vislumbra suas possibilidades de desenvolvimento, apoiando-se no diálogo como objeto de estudo.

A partir desse momento, a atividade científica e pedagógica de Jakubinski está ligada ao ILJaZV, instituto no qual ele se torna secretário científico ${ }^{19}$, e, de 1933 a 1936, diretor. Além dessa ocupação principal, Jakubinski leciona em outros estabelecimentos. De 1923 a 1927, ele é responsável dos Cursos de técnica da fala ${ }^{20}$. De 1924 a 1928, ele é inspetor da seção de Leningrado da Glavnauka²1. De 1927 a 1929, ele é professor no Instituto pedagógico Herzen. Ao longo desses anos, Jakubinski trabalha, durante certo tempo, no Instituto de história das artes ${ }^{22}$ e no Instituto jafético (1924-1927) ${ }^{23}$.

A partir da segunda metade da década de 1920, Jakubinski lidera, portanto, um trabalho científico e pedagógico e uma intensa atividade administrativa de organização da pesquisa científica em Leningrado. Ele se encontra, efetivamente, no centro das novas direções de pesquisa e aproveita a possibilidade de exercer certa influência nessa cidade. Como observa A. Leontiev, um dos seus biógrafos, esse tipo de atividade intensa caracterizava bem os alunos de Baudouin de Courtenay, que jamais foram "estudiosos acadêmicos" (LEONTIEV, 1986, p. 4) por assim dizer. Na verdade, Baudouin de Courtenay buscava atuar para que as pesquisas científicas dos seus alunos encontrassem uma aplicação prática em pedagogia ou então para o desenvolvimento da cultura.

As pesquisas de Jakubinski durante esse período refletem sua orientação pedagógica e são, em grande parte, dedicadas ao estilo oratório ou a conselhos

18 Essa revista foi fundada em 1923 por alunos de Baudouin de Courtenay sob a égide do Instituto de fonética e estudo prático de línguas. O redator-chefe, Lev Scerba, declarou em seu artigo introdutivo que o objetivo da revista era o abandono da antiga linguística histórico-comparativa em prol do estudo da linguagem viva enquanto fenômeno dado na experiência, da sintaxe viva, da semântica e da estética da língua.

19 A função de secretário científico consistia em organizar o trabalho dos candidatos à preparação de uma tese de kandidat ou dos candidatos de doutorado.

20 Os Cursos de técnica da fala foram organizados em 1923 como uma dependência do Instituto da Palavra Viva (tendo Jakubinski participado da criação deste em 1918). Em 1924, esse instituto era definitivamente fechado (Cf. Ivanova, 2005).

21 Órgão administrativo de direção e de coordenação de pesquisa científica e de propaganda da ciência e da cultura, ele existiu de 1922 a 1933.

22 O Gosudarstvenyj institut istorii iskusstv (GIII) foi fundado depois da revolução de outubro de 1917 com base no Instituto de história das artes do conde Zubov. Em 1921, o Instituto de história das artes foi transformado em um estabelecimento que havia como objetivo pesquisas na teoria e a história das artes. Muitos pesquisadores e artistas de vanguarda, assim como críticos literários formalistas, trabalharam nesse estabelecimento.

23 O Instituto jafético foi fundado em 1921-1922 por iniciativa de N. Marr. Em 1931, ele foi transformado em Instituto da língua e do pensamento. 
aos escritores iniciantes. Seu artigo Otraženije praslavjanskogo ě v čakavskom [O reflexo do ě protoeslavo em chakavien], que trata de gramática histórica e comparada e que foi publicado em alemão, ocupa um lugar importante. É graças a esse artigo que o nome de Jakubinski entrou na história dos estudos eslavos, sob o nome de “lei de Jakubinski-Meyer” (MIHALJEVICH, 2002).

Foi, sem dúvida, a grande atividade de Jakubinski na pesquisa de novos caminhos em linguística e seus esforços para se distanciar da problemática indo-europeísta que o conduziram a cooperar com N. Marr (1864-1934) 24. A. Leontiev (1986, p.8) relata um comentário de Jakubinski datado da década de 1930, no qual este último explica o abandono das pesquisas no campo indo-europeu.

A hipótese da protolíngua [...] estava absolutizada e hipertrofiada, ela tinha se tornado
um meio aplicado mecanicamente para explicar as similaridades entre as línguas, em
detrimento de suas diferenças. O método comparativo tinha se transformado em uma
espécie de chave-mestra que abria todas as portas.

Durante o inverno de 1925-1926, Jakubinski fez uma apresentação na seção de linguística geral do ILJaZV sobre o tema: $K$ voprosu o vzaimootnošenii meždu jafetičeskim jazykoznanijem i indoevropeistikoj [As relações entre a linguística jafética e os estudos indo-europeus] e, em 1926, ele publicou um artigo escrito a partir de posições da Nova teoria da linguagem: $K$ paleontologii nazvanija dlja « poloviny» [Paleontologia de designações da 'metade']. 0 que interessa Jakubinski na teoria linguística de Marr é o método semântico em estágios, a ideia que a evolução da sociedade leva à evolução do pensamento e, consequentemente, à evolução da língua que é falada. Encontraremos alusões a essa ligação entre língua, sociedade e pensamento em seu "Sobre a fala dialogal”, o que não é nada surpreendente dado que, nesses anos, na Rússia soviética, assistia-se à prática de uma psicologia social e de uma reflexologia nas quais a questão da relação entre uma situação particular, o pensamento e sua expressão verbal ocupa um espaço central. Parece que o interesse de Jakubinski pela semântica, a linguagem vista como atividade, herdada de Baudouin de Courtenay, e as considerações sobre a ligação entre língua e sociedade podem explicar seu entusiasmo pelo arrismo ${ }^{25}$.

Na década de 1930, Jakubinski prossegue com sua intensa atividade

24 N. Marr, linguista de origem georgiana, arqueólogo, etnólogo, acadêmico e diretor do Instituto jafético em Leningrado. Sua Nova teoria da linguagem torna-se, no fim da década de 1920, doutrina quase oficial na URSS e a recusa em aderir a essa doutrina resultava em fortes repressões políticas. Encontraremos uma análise do "marrismo" em Sériot, 2005 e Velmezova, 2007.

25 É interessante observar que a necrologia redigida por Jakubinski-Lemberg, em 1949, destaca o papel positivo que a influência de Marr desempenhou para Jakubinski (Jakubinskaia-Lemberg, 1949 , p. 6), enquanto que o prefácio de A. Leontiev tenta de todas as formas encontrar desculpas (Leontiev, 1986, p. 7). 
educacional, científica e administrativa. Em 1931, ele é submetido a uma “purga do aparato de Estado", porém, apesar de suas origens aristocráticas e de não ser membro do Partido comunista, ele foi mantido em seu posto ${ }^{26}$. Conforme mencionado anteriormente, de 1933 a 1936, ele dirige o Instituto de linguística da Academia de ciências e continua ensinando no Instituto pedagógico Herzen e no Instituto pedagógico regional Pokrovski. Em 19361937 ele é enviado a Ankara para ensinar russo no Instituto de língua, história e geografia, período no qual ele estuda turco (LEONTIEV, 1986, p. 10).

Conservando seu interesse pelo ensino da língua na escola, ele participa da elaboração de programas escolares, de manuais e da formação de professores. Em 1930, ele começa a colaborar na revista Literaturnaja učeba ${ }^{27}$, na qual ele publica, além de alguns trabalhos de sociolinguística, uma série de artigos destinados a formar, nos escritores iniciantes, uma cultura linguística. No mesmo ano, ele escreve uma série de artigos para um Manual de russo.

Analisando esses trabalhos, A. Leontiev acredita que eles não representam um maior valor científico por causa do seu "sociologismo vulgar" (LEONTIEV, 1986, p. 6). Acreditamos, contudo, que, para um historiador de ideias linguísticas, esses trabalhos são de grande interesse, pois eles são um bom exemplo do estado de avanços da sociolinguística na URSS na década de 1930.

Por essa razão, é preciso atribuir um espaço especial ao seu artigo "Ferdinand de Saussure sobre a impossibilidade de uma política linguística", apresentado, inicialmente, sob a forma de apresentação oral em 1929 e publicado, posteriormente, em 1931. Lembremo-nos que, nessa época, as questões de política linguística eram extremamente atuais para os linguistas soviéticos. Era preciso criar alfabetos para as línguas não escritas, conceber dicionários, gramáticas, manuais, se encarregar de codificar as línguas, ensinar a ler e a escrever às imensas massas de analfabetos: todas essas tarefas práticas necessitavam de um esclarecimento teórico. No primeiro plano das reflexões, encontravam-se a definição da noção de "língua literária" (ou seja, normatizada) e a possibilidade de influência do indivíduo e da sociedade sobre os processos linguageiros. Esse artigo de Jakubinski dá uma boa ideia da posição da maioria dos linguistas soviéticos.

26 Fundos do Instituto Herzen, PPS, arquivo pessoal n 1931 , arquivo pessoal $n^{\circ} 179$.

27 Essa revista foi fundada pelo escritor Maxime Gorki em 1930 para ensinar a profissão de escritor aos escritores originários do campesinato ou da classe operária. Na revista, eram encontrados artigos teóricos sobre a linguística e a ciência da literatura, assim como análises concretas de obras de jovens escritores iniciantes. V. Volochinov, autor de Marxismo e filosofia da linguagem, e um dos alunos de Jakubinski publicaram, nessa revista, três artigos importantes nesse mesmo ano de 1930: "O que é a língua e a linguagem”, “A construção do enunciado", “A palavra e sua função social”. 
Outro ponto a destacar: paralelamente a esses trabalhos “marxistas”, Jakubinski se voltou, novamente, para a linguística histórico-comparativa e, em 1936, em pleno período marrista, ele faz a apresentação Elementy jazykoznanija $i$ istorii jazyka $v$ srednej škole [Elementos de linguística e de história da língua na escola secundária] ${ }^{28}$. Os outros trabalhos de Jakubinski do final de década de 1930, publicados de maneira póstuma, mostram que ele dedica muito tempo à história da língua russa e se distancia, pouco a pouco, da teoria marrista.

É provável que o profissionalismo de Jakubinski no campo da linguística e o seu embasamento em fatos concretos da língua lhe mostrassem claramente 0 caráter declarativo e especulativo da Nova teoria. Em 1938, de volta à Turquia, ele trabalha como redator científico da Xrestomatija po istorii russkogo jazyka [Crestomatia de história da língua russa] de Obnorski e Barxudarov. Igualmente, ele produz um Učebnik po istorii russkogo jazyka dlja pedinstitutov [Manual de história da língua russa para os institutos pedagógicos] ${ }^{29}$ e prepara uma Kratkij očerk obrazovanija sovremennogo literaturnogo jazyka (vvedenije knormativnoj grammatike russkogo jazyka, izdavaemoj Akademijej nauk) [Breve análise sobre a formação da língua literária moderna (Introdução à gramática normativa do russo editada pela Academia de ciências)] $]^{30}$, mas esses trabalhos nunca foram publicados. A. Leontiev (1986, p. 9) pensa que a razão é que esses textos não eram "bem aceitos" por causa de sua não conformidade ao marrismo, mas Jakubinskaia-Lemberg aponta como motivo, na verdade, o início da Segunda Guerra Mundial (JAKUBINSKAIA-LEMBERG, 1949, p. 7).

Depois de tantos anos é difícil saber exatamente o que aconteceu. Certo é que toda oposição ao marrismo era perigosa, e o exemplo de Polivanov, fuzilado em 1938, levava à reflexão. A história da língua podia ser um refúgio. Mas essa fuga diante da doutrina marrista se pagava com o preço do silêncio imposto. Jakubinskaia-Lemberg insiste, em 1949, na sua fidelidade ao marxismo e à política do partido, como que para justificá-lo.

Parece-nos, entretanto, que o fato de Jakubinski ter se direcionado para a gramática histórica não está limitado a considerações ideológicas e políticas. Para um cientista que se interessara durante tantos anos pela relação entre língua e pensamento e que se entusiasmara pela teoria dos estágios de Marr, o retorno à história da língua era uma evolução bem compreensível. Basta citar essa passagem de 1932, na qual ele diz: "não apenas a estrutura da língua atual, mas mesmo os acontecimentos particulares dessa língua não podem

28 Republicado por Leontiev na antologia de 1986, p. 86-97.

29 Jakubinski menciona esse manual na lista de publicações como aceito para edição em 1941.

30 Esse livro é também mencionado por Jakubinski como "em preparação para edição na Academia de ciências". 
ser compreendidos sem uma abordagem histórica" (JAKUBINSKI, 1932). Por essa razão, a revisão de suas posições teóricas e sua vontade de compreender a evolução da língua a partir de fatos concretos levaram Jakubinski em direção à história da língua que remonta aos períodos mais antigos. Podemos ver aí a influência de Saxmatov sobre a relação entre história da língua e história da sociedade e a influência de seus trabalhos sobre a história do russo antigo.

Contudo, esses estudos de Jakubinski corresponderam ao período difícil da guerra, no qual a publicação de trabalhos teóricos sobre a história da língua não era uma necessidade vital. Especialmente desde que Jakubinski recusouse a deixar cidade de Leningrado [novo nome de Petrogrado, a partir de 1924, N.R.T] enquanto foi sitiada, vivendo nela os 900 dias de bloqueio. Em condições dramáticas de frio e de fome, vivendo no edifício do Instituto pedagógico Pokrovski com a luz de um lampião, ele escreveu um manual de introdução à linguística, no qual ele queria "fazer um balanço de suas concepções científicas sobre os problemas gerais da evolução das línguas" (JAKUBINSKAIA-LEMBERG, 1949, p. 7). Quando, em pleno bloqueio, o Instituto Herzen reabriu suas portas, Jakubinski retomou seu trabalho de professor. Ele continuou a juntar materiais sobre a história do russo do século XVII. Mas as condições difíceis de vida durante o bloqueio aceleraram a sua morte em agosto de 1945.

Sua mulher, E. Jakubinskaia-Lemberg (1895-1961) ${ }^{31}$, especialista em estudos eslavos, trabalhando no Departamento de estudos eslavos da Universidade de Leningrado, conservou os trabalhos de Jakubinski e publicou os que se relacionavam à história do russo. Em 1953, V. Vinogradov (1895-1961) 32, que foi ao lado de Jakubinski às fontes do formalismo russo, sendo seu colega no ILJaZV e tendo, ele mesmo, sofrido as repressões stalinistas, publicou o último livro de Jakubinski Istorija drevnerusskogo jazyka [História do russo antigo] com seu prefácio. No entanto, tudo isso não salva do esquecimento o nome de Jakubinski, que desapareceu da história da linguística por muitos anos.

31 Especialistas de línguas eslavas e fino-úgricas, ela dirigiu o departamento eslavo da faculdade de filologia da Universidade de Leningrado entre 1948 e 1955.

32 V. Vinogradov, acadêmico, diretor do Instituto da linguística de 1950 a 1954 e depois entre 1958 e 1969. No início de sua carreira científica, ele era próximo da OPOJAZ e publicou diversos trabalhos dedicados à língua das obras literárias. Nesses trabalhos, ele desenvolveu diversos temas que foram retomados em seguida por Bakhtin (a "fala de outrem", a “voz", a organização polifônica de uma obra). Ele conhecia bem Jakubinski e foi seu colega no ILJaZV. Em 1934-36 ele foi preso e deportado no "negócio dos eslavos", depois deportado novamente em 1941-43. Assim como Jakubinski, ele abandonou as ideias do formalismo russo e se dedicou à língua dos escritores (Gogol, Dostoiévski, Pouchkine). Quando ele estava exilado na Sibéria (em Tobolsk), ele escreveu sua Gramática do russo, publicada em 1947, assim como trabalhos sobre a imagem do autor. Uma vez de volta a Moscou, na década de 1950, ele se tornou um símbolo da linguística soviética pós-Stalin oficial. 


\section{Lev Jakubinski (1892-1945): the destiny of a Russian linguist}

Abstract: Although Lev Jakubinsk (1892-1945) was one of the founders of Russian formalism, was a source of ideas for the theory of dialogism proposed by Volochinov (1895-1936) and was referenced by L. Vigotski (1896-1934), he remains unknown in the West. This paper seeks to fill in this gap, describing the scientific journey of this Russian linguist, who presented many innovative ideas for his time in his work. In addition the life and scientific journey of Lev Jakubinski are an open door to the discussions and aspirations of the scientists of this time, when social turmoil coincided with intensive development in the natural and social sciences.

Keywords: Dialogism. Dialog. Speech linguistics. Living language. Marxism. Soviet Russian linguistics. 


\section{REFERÊNCIAS}

Budagov, Ruben. L.P. Jakubinskij. Kak i počemu v istorii jazykov Jakubinskij. [0 como e o porquê na história das línguas]. In: Portrety jazykove dov XIX-XX vekov. Iz istorii lingvističeskxh učenij. Moskva: Nauka, p. 123-153, 1988.

CHKLOVSKI, Viktor. Sobranijesočinenij v 3-x tomax [Obras escolhidas em 3 volumes]. t. 1. Moskva: Xudožestvennaja literatura, 1973.

. Gamburgskij sčet [O torneio de Hamburgo]. Moskva: Sovetskij pisatel', 1990.

Eichenbaum, Boris. “Kaksdelana « Šinel » Gogol’a” [Como é feito « O Capote » de Gogol]. Poètika, p. 151-163, 1919.

IVANova, Irina. Les contacts franco-russes en phonétique expérimentale: l'abbé Rousselot et ses stagiaires russes. Slavica Occitania, Toulouse, n¹7, p. 83-91, 2003.

'Un dialecte sorabe oriental' de Ščerba, premier essai de linguistique de la parole. Slavica Occitania, Toulouse, n² 20, p. 113-130, 2005.

. Zagadka Instituta Živogo Slova [O enigma do Instituto da Palavra Viva]. In: LÄHTEENMÄKI, Mika et al.. Proceedings of the XII International Bakhtin Conference Jyväskylä. Department of Languages, University of Jyväskylä, Finland, p. 94-106, 2006.

. L'opposition 'langue poétique/langue pratique' dans la conception linguistique de Lev Jakubinskij : discours sur les langues et rêves identitaires. Cahier de l'ILSL. Université de Lausanne, n²6, p. 113-128, 2009.

JAKUBINSKAIA-LEMBERG, Erika. Professor L.P. Jakubinskij. Učenyje zapiski Leningrads kogo gosudarstvennogo universiteta, $n^{\circ}$ 97, serija filologičeskix nauk, vyp. 14, p. 3-9, 1949.

JAKUBINSKI, Lev. O zvukax stixo tvornogojazyka. [Sobre os sons da linguagem versificada]. In: Sbornik pó teorii poètičes kogojazyka, vol. 1, Petrograd, p. 1630, 1916.

. Skoplenieo dinakovyx plavnyx v praktičeskom i poetičes komjazyke [Acumulação de soantes idênticos na língua prática e na língua poética]. In: 
Sbornik po teorii poètičes kogojazyka.vol. 2.Petrograd, 1917.p. 15-23.

. O suščestv leniez vukovo goedinoobrazija v tvorčestve Lermontova [A realização da uniformidade sonora na obra de Lermontov]. In: Sbornik pó teorii poètičes kogojazyka. Petrograd, vol. 2, 1917, p. 63-70.

. O poètičes komglossèmo sočetanii [Sobre a combinação glossemática poética]. In: Poètika. Petrograd, 1919. p. 5-12.

. O dialogičeskoj reči. [Sobre a fala dialogal]. Russkaja reč’, n¹, p. 96194, 1923.

, Ferdinand de. Sossjur o nevozmožnosti jazykovoj politiki. [Ferdinand de Saussure sobre a impossibilidade de uma política linguística]. In: Jazyko vedenie i materializm. Moskva, 1931. p. 91-104.

. Očerki po jazyku. [Ensaios sobre a linguagem] (em colaboração com A. M. Ivanov). Literaturna jaučeba [reedição revista e corrigida dos artigos]. Moskva - Leningrad, GIXL. 1932.

. Istori jadrevne russ kogojazyka. [História do russo antigo]. Moskva, 1953.

. Jazyk i ego funcionirovanie [A linguagem e seu funcionamento] (Alexis Leontievéd). [Antologia de artigos], Moskva: Nauka, 1986.

LeOntIEV, Alexis. Žizn' i tvorčestvo L.P. Jakubinskogo [A vida e a obra de L. Jakubinskj]. In: Jakubinski, p. 4-12, 1986.

- Kommentarii. O dialogičeskoj reči. [Comentários. A fala dialogal], In: Jakubinski, p. 199-200, 1986.

Lutovinova, Irina. Filologičeskij fakul'tet Sankt-Peterbugskogo gosudarstvennogo universiteta: materialy $\mathbf{k}$ istori i farkul'teta [A Faculdade de Filologia da Universidade de São Petersburgo: materiais para a história da Faculdade]. Bogdanov S. (éd.), 4e édição revista e corrigida. Sankt-Peterburg: Filologičeskij fakul'tet, 2007.

MıHALJEVICH, Milan. Slavenska poredbena gramatika, I. dio, Uvod I fonologija [A gramática eslava comparada]. Zagreb: Školska knjiga, 2002. Disponível em: http://en.wikipedia.org/wiki/Jakubinskij's_law.

SÉRIOT, Patrick. Un paradigme perdu: la linguistique marriste, Cahiers de l'ILSL(Éd.). Université de Lausanne, n² 20, 2005. 
Tynjanov, Juri. Poètika. Istori ja literatury Kino [Poética, história da literatura, cinema], Moskva: Nauka, 1997.

Velmezova, Ekaterina. Les lois du sens: la sémantique marriste. Berne: Peter Lang, 2007.

ZAPISKI INSTITUTA ŽIVOGO SLOVA. [Notas do Instituto da Palavra Viva], Petrograd, vyp 1, 1919.

RECEBIDO: Novembro de 2012.

APROVADO: Março de 2013. 